\title{
A MILP Model for the Long Term Academic Staff Size and Composition Planning in Public Universities
}

\author{
${ }^{*}$ R. de la Torre ${ }^{\mathrm{a}}$, A. Lusa $^{\mathrm{b}}$, M. Mateo ${ }^{\mathrm{a}}$ \\ ${ }^{a}$ Department of Management / ETSEIB. Universitat Politècnica de Catalunya. \\ Av. Diagonal 647, 7th floor, 08028 Barcelona, Spain \\ ${ }^{b}$ Department of Management / IOC / ETSEIB. Universitat Politècnica de Catalunya. \\ Av. Diagonal 647, 11th floor, 08028 Barcelona, Spain
}

\begin{abstract}
This paper proposes a model for dealing with the long term staff composition planning in public universities. University academic staff is organized in units (or departments) according to their field of expertise. The staff for each unit is distributed in a set of categories, each one characterized by their teaching hours, cost and other specificities. Besides the use for planning (and updating a plan), the model can be used to assess the impact that different strategies may have on the personnel costs and the structure of a university. The proposed model is formulated generally, so it can be applied to different types of universities attending to their characteristics. The model is applied to a real case and validated by means of a computational experiment considering several scenarios. The analysis is focused on achieving a preferable academic staff composition under service level constraints while also minimizing the associated economic expenditures considering a long term horizon. The results show that the model successes in approaching the staff composition to a previously defined pattern preferable one.
\end{abstract}

Keywords: Strategic Staff Planning, Long Term Staff Planning, MILP, KIO/KIF, KIBS.

\section{Introduction}

Universities are Knowledge Intensive Organizations, i.e. KIOs (Starbuck, 1992) in which having academic staff with certain knowledge and expertise may require several years (workers, which are highly qualified, are not easily replaced). Having the right academic staff size and composition in a university, as in other organizations, depends on decisions that must be taken in advance enough (for example, to have a certain amount of professors in a certain year is possible only if staff with the right profile is hired some years before and trained and promoted progressively from lower categories). Without an accurate strategic planning the available academic staff may not be appropriate for the requirements of the university, both regarding teaching capacity (teaching hours) and research and knowledge transfer activities. Thus, it is essential to have tools that enable an adequate planning for long term (strategic) academic staff size and composition. This is especially important for public universities, where there are normally strict regulations that do not permit to adjust easily the staff composition.

In most countries universities have been growing (both in number and size) as the education level of the population was becoming higher. The size of the academic staff in public universities has been increasing while the economic situation of countries was good and the demand for university courses was high. Generally, the academic staff was growing, but without the result of an analytical planning procedure and only as the result of short-term decisions taken normally with a reduced horizon (without considering for example future retirements). As Rowley et al. (1997), Birnbaum (2000) and Lillis (2006) pointed out that usually the planning of the workforce in universities is mostly short-sighted and motivated from the need of solving punctual problems, or intensively explored for a short period of time only to be abandoned later, without any real attempt to assess their effectiveness.

The lack of an accurate planning may cause a too high cost of the staff, or a shortage or a surplus of academics with certain knowledge and/or expertise in some areas or departments or an inappropriate staff composition; note that, as Maenhout and Vanhoucke (2013) state, in a university, where knowledge plays an important role, not only the economic criteria are necessary to be considered for determining a staff composition. Academic staff tasks include, besides of teaching, doing research and participating in knowledge transfer projects (also keeping some management responsibilities like a head of a department does). Hence, people who are able to do these tasks and also people who are able to manage these tasks are needed. This gives raise to the need of achieving an academic workforce with reasonable costs and a proper capacity in terms of research and knowledge transfer. Both costs and capacity outperforming those tasks grow with the category so both criteria have to be taken into account when planning the staff size and composition, reaching to a balanced workforce.

If staff strategic planning is an important activity for any organization (its performance may depend on this), this is especially true for public universities for two reasons: first, because the flexibility to correct the size or the composition of the

*Corresponding author: Rocio de la Torre. Tel: +34-934-017-444;

E-mail: maria.rocio.de.torre@upc.edu 
staff in the medium or short term is very limited (due both to regulations on promotions and hiring and to the difficulty in finding people with enough expertise and knowledge in some areas); and second, because the available budget to use on staff decisions (mainly on hiring and promotions) is tight, especially in situations of economic crisis like the actual one, with public funding becoming lower and lower. Resources have to be used in an efficient way, and this means leading to the workforce (size and composition) that covers the needs of the organization in an appropriate way, which obviously is not possible if a correct staff plan is designed in advance. Besides, it is important to note that the staff planning in universities is also a very relevant problem for other reasons, such as the competition to attract the best professors, pupils and research funding (Taylor and Miroiu, 2002).

The numerous changes (both external and internal) that Higher Education Institutions (HEIs) have been facing during the last decades motivated for the first time in the eighties of the $20^{\text {th }}$ century the development of the strategic management in universities (based on the experiences in companies). In the eighties also took place the widely movement of NPM (New Public Management), which hold the hypothesis that market oriented management of the public sector would lead to greater cost-efficiency for governments, without having negative side-effects on other objectives and considerations (Hood, 1991). However, the staff planning was not included in the strategic management (Llinàs-Audet et al., 2010). Several universities have carried out actions for the definition of the strategic planning. That is why the strategic staff planning in universities is a hot topic and very timely. In this sense, and as Hunt et al. (1997) pointed out, the strategic staff planning would permit universities to optimize their resources, thus achieving greater institutional success (greater international projection, better academic environment, etc.). However, and despite the fact that several studies demonstrate that the number of strategic management-related practices is increasing (Clark, 1998, 2003; Lounsbury, 2001; Jarzabkowski, 2003; Shattock, 2003; Agasisti et al., 2008), this positive change in the tendency is constrained by the academic and institutional regulations in universities.

Regardless the importance of the staff strategic planning for the design and viability of all type of organizations, few studies concerning the determination of the strategic planning for KIOs are reported in the literature (O'Brien-Pallas et al., 2001, Zeltyn et al., 2011). In fact, as noted by Machuca et al. (2006) and Roth and Menor (2003), a gap between the increasing importance of the management in service organizations and the related studies is identified.

Since the early production planning model of Holth et al. (1960), which considered hiring and firing of personnel in a very simple way, few authors have dealt with similar problems, mainly addressing manufacturing industry (Wang et al., 2006; Chou et al., 2007; Ren-quian et al., 2007; Geng and Jiang, 2009; Geng et al., 2009), but no one with the problem that is being addressed in this paper. Actually, to the best of our knowledge, there are no works in the scientific literature that propose tools for solving the problem of determining the size and composition of the academic staff of a public university and at the same time taking into account the regulations on hiring, firing and promoting, optimization criteria and relevant characteristics for this kind of organization as well. These characteristics are such as the heterogeneity of the workforce and the need of considering other factors apart from those purely economic, as the required service level, while determining the preferable staff composition (in size and expertise).

Our problem is partially considered in a few papers. For instance, Corominas et al. (2012) propose a model for an aggregate planning problem that includes the hiring and firing of workers considering a learning period, but the transfers between categories (promotions within a given pathway) nor the staff composition criteria are not included there. In the same line Song and Huang (2008) present a model for hiring, firing and transferring employees (who are considered homogeneous, i.e with the same capacity and skills) among different units and the main optimization criterion is to minimize the personnel cost. Such problem is also addressed in Ahn et al. (2005), but considering heterogeneous workers in this case.

Attending to the scarcity of literature concerning the long term staff planning in KIOs in general and in public universities in particular, the main contributions of this paper are: (1) to formalize the problem considering public university characteristics, especially those regarding planning criteria (such as achieving a certain composition) and those regarding hiring, firing and promoting possibilities (category pathways); (2) to propose a new Mixed Integer Linear Programming (MILP) model for dealing with the problem; and (3) to give some managerial insights that come from a computational study and the application of the model to a real case.

The paper is organized as follows: Section 2 describes the problem; Section 3 includes the description of the proposed mathematical model formulation; Section 4 presents a case study; Section 5 includes a computational study; and finally the conclusions and proposed further work are detailed in Section 6.

\section{Problem description}

Strategic staff planning may involve many kinds of decisions. Some of them (for example, the number of people to hire, dismiss and promote) can be taken by applying a formalized planning procedure (for example, based on a mathematical model, as it is proposed here), and others (such as deciding the kind of staff pyramid that is appropriate for a given university) would require other kind of procedures, probably not so formalised and more qualitative. The concrete strategic staff planning problem here addressed consists of determining, for each period of a long term horizon, the size and the composition of the academic staff for a public university. The university is supposed to be organized in units (for example 
schools, faculties or departments) and each member of the academic staff belongs to one and only one unit. Transfers between units are not considered since such decisions are quite singular and require dedicated analyses.

Each academic belongs also to a category, being possible to change from one category to another/s during the planning horizon, according to the established rules, which in public universities are normally clear and rigid. It is possible for a person to promote to a higher category once the required merits (for the upper category) are reached and, of course, if a job position in that upper category has been created or is available.

In most public universities there are also part time lecturers, which are hired only for teaching purposes and provide students with real world experience thus complementing their education. The proportion hold by these workers in university may be bounded by the government or by the university.

Of course the exact career pathway depends on the country/university legislation, but it can be considered that most public universities have common characteristics. In all of them there are temporary categories (this means that if after a certain time the person has not changed to an upper category, he/she is dismissed) and permanent categories. The academics that are needed for a certain category can come from a lower category (an internal promotion) or from the labour market. Figure 1, presented and more widely described in Section 4, gives an example of a career pathway for the university workers, more widely described in Section 4.

There are two types of categories for workforce: temporary and permanent. In temporary categories, just after a member of the staff obtains his/her graduate and $\mathrm{PhD}$, it is mandatory to follow a path of a certain duration. In these categories, the contracts are typically renewed each year. On the other hand, staff in permanent categories may follow two possible pathways: contractual and public/tenure. Personnel in contractual pathway can be dismissed, but on the other hand, the progression is not as hard as in the public pathway is. Besides, there can be part-time lecturers.

The main differences between categories are the cost (salaries), the number of teaching hours per person, the responsibilities that can undertake and the productivity and quality of tasks regarding research and knowledge transfer. The latter are not easily quantified, while the salary and the amount of teaching hours are usually well specified and, of course, objective.

Since teaching is the first mission of a public university, the academic staff is usually sized according to the expected teaching needs (which are supposed to be known), normally allowing an oversizing to face reductions in real capacity (unexpected problems, discounts of teaching hours to people in charge of other responsibilities like head of the department, etc.) and to take into account that, due to courses' timetables, it is not usually possible to perfectly adjust capacity to requirements.

If minimizing the cost while ensuring teaching hours was the main driver, a staff with a high number of members with a low category (or even part time lecturers) would be probably the result of a planning process. However, even if cost minimization and budget constraints must be taken into account, a public university cannot forget research and knowledge transfer. So, it has to ensure that the number of professors in the academic staff can undertake these tasks with a high level, leading research teams and projects. To take this into account, a preferable staff composition (or pyramid), which is a strategic issue that has to be determined by the government of the university (or even the region), can be considered. In some universities or countries there is a high number of assistants, who teach for a lot of hours, and a low number of professors supervising them; in others, the situation is almost the opposite. Different pyramids or university models may have different advantages and disadvantages, but it is not the purpose of the paper to discuss this subject, as it is to give tools for planning the academic staff size and composition according to, among others, the criteria of getting a composition similar to a preferable one.

Below, the characteristics of the problem are summarised:

- The initial size and composition of the staff are known.

- $\quad$ Forecasted layoffs are known.

- $\quad$ Each member of the academic staff belongs to one unit (e.g., department) and category.

- The maximum number of annual teaching hours for each category is known.

- There is a forecast of the number of teaching hours that will be required for each unit (e.g., department) and year. The capacity (measured in teaching hours) must not be less than the required one multiplied by a coefficient that can be positive (a surplus is desired), zero or negative (a shortage would be allowed).

- The academic pathway is known (e.g. Figure 1), and also the proportion of people from a category that acquire the merits to promote to another category, which gives an upper bound of the number of people that can pass from one category to another.

- Decisions to be taken include the number of people to hire, to dismiss and to promote.

- The preferable composition of the staff, in terms of categories, is given by the government of the university.

- The objective is to minimise a function that contains the cost of the staff (salaries and dismissals) and the discrepancy between the composition of the staff and the desired one.

\section{Model formulation}


The problem has been modelled as a Mixed-Integer Linear Program (MILP). As it can be seen, the model is general enough and hence can be applied to a wide range of universities from different countries for solving the planning of the academic staff size and composition. As it usually happens, it might be adapted to each particular case.

The data and parameters are respectively shown in Table 1 and Table 2. Variables are divided in two groups: decision variables (Table 3) and the rest (Table 4). The Section finishes with the model formulation.

Table1 Data description

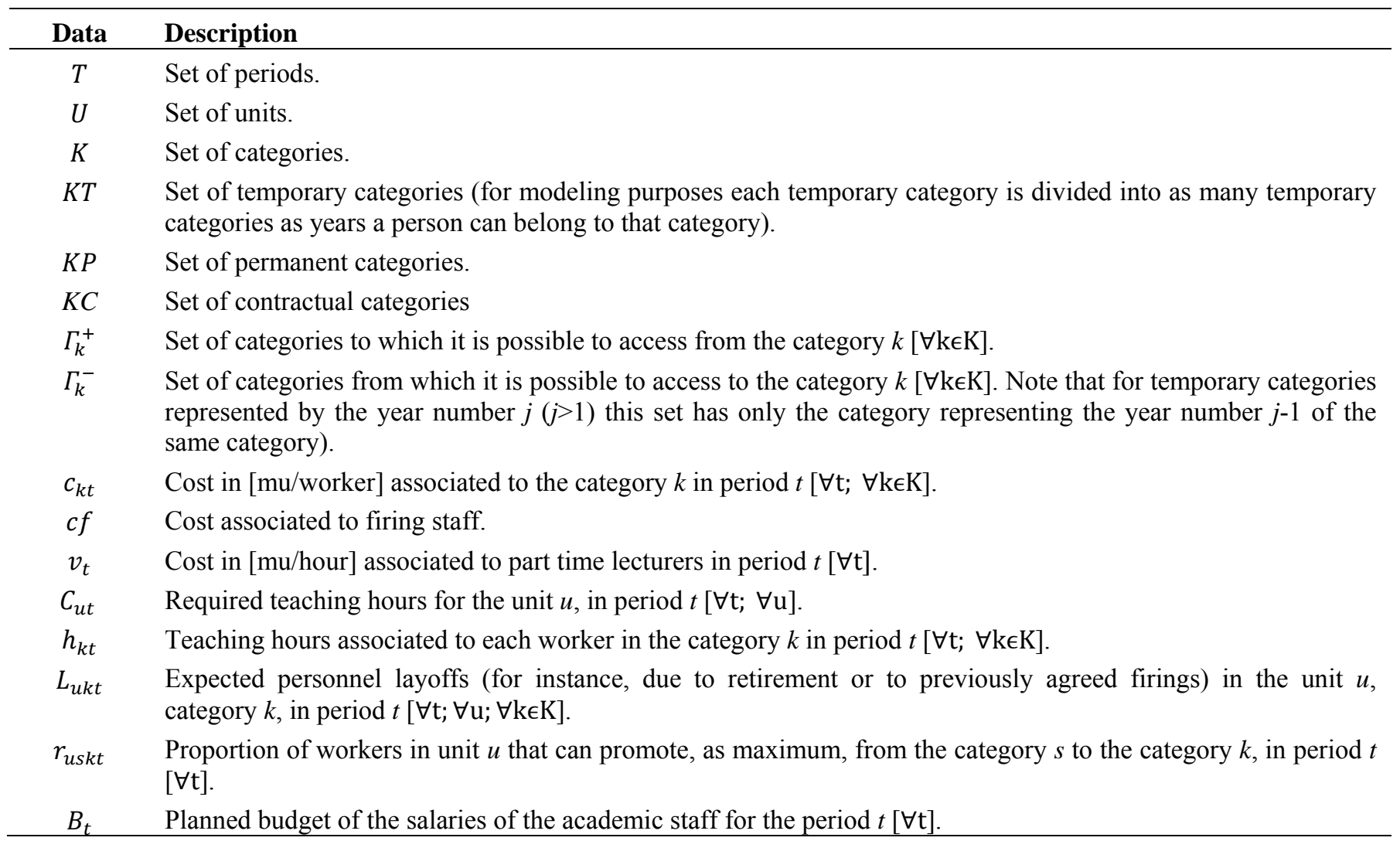

Table 2 Parameters of the problem

\begin{tabular}{cl}
\hline Parameter & Description \\
$U P_{k t}, L P_{k t}$ & $\begin{array}{l}\text { Preferable bounds for the proportion of academic staff that belongs to the category } k \text { in the period } t \text {. This } \\
\text { condition is not hard, but non-compliance is penalized. }\end{array}$ \\
$\alpha_{u t}$ & $\begin{array}{l}\text { Excess of teaching hours that should have, at least, the unit } u \text { in the period } t \text { [ } \forall \mathrm{t}] \text {. Note that, even if it is not } \\
\text { usual, this parameter could be negative if a shortage in the capacity is allowed; this would mean a worsening } \\
\text { in the service level (for example, because the number of students in a teaching room is too high). }\end{array}$ \\
& $\begin{array}{l}\text { Penalty associated to the discrepancy between the preferable and the planned composition of academic staff } \\
\text { in the category } k, \text { in the period } t[\forall \mathrm{t}] .\end{array}$ \\
$\lambda_{t}$ & $\begin{array}{l}\text { Penalty associated to the maximum discrepancy between the preferable and the planned composition of the } \\
\text { academic staff, in the period } t[\forall \mathrm{t}] .\end{array}$ \\
& Penalty associated to the maximum discrepancy between the preferable and the planned workforce.
\end{tabular}

Table 3 Decision variables

\begin{tabular}{ll}
\hline Variable & Description \\
\hline $\mathrm{w}_{\mathrm{ukt}} \in \mathbb{Z}^{+}$ & Indicates the number of workers of the unit $u$, category $k$ and period $t[\forall \mathrm{t} ; \forall \mathrm{u} ; \forall \mathrm{k} \in \mathrm{K}]$. \\
$\mathrm{A}_{\mathrm{ut}} \in \mathbb{R}^{+}$ & Indicates the capacity assigned to part time lecturers in the unit $u$ in period $t[\forall \mathrm{t} ; \forall \mathrm{u}]$. \\
$\mathrm{Q}_{\mathrm{uklt}} \in \mathbb{Z}^{+}$ & $\begin{array}{l}\text { Indicates the number of workers who access to the category } l \text { from the category } k \text {, in the unit } u, \text { in the period } t \\
{[\forall \mathrm{t} ; \forall \mathrm{u} ; \forall \mathrm{k} \in \mathrm{K}] .}\end{array}$ \\
$\mathrm{w}_{\mathrm{ukt}}^{+} \in \mathbb{Z}^{+}$ & Indicates the number of workers who are hired from the labor market for the unit $u$ and category $k$, in the period \\
\hline
\end{tabular}




\begin{tabular}{|c|c|}
\hline Variable & Description \\
\hline & $\begin{array}{l}t[\forall \mathrm{t} ; \forall \mathrm{u} ; \forall \mathrm{k} \in \mathrm{K}] \text {. Note that for categories representing the year number } j(j>1) \text { of a temporary category usually } \\
\text { this variable should be } 0 \text {. However, this is not constrained in the model because in some cases it might be } \\
\text { possible to hire people for a temporary category with a contract of less years than the maximum permitted (for } \\
\text { example if the person has already worked in that category during almost one year in another university). }\end{array}$ \\
\hline $\mathrm{w}_{\mathrm{ukt}}^{-} \in \mathbb{Z}^{+}$ & $\begin{array}{l}\text { Indicates the number of fired workers (excluding the previously forecasted) in the unit } u \text { and the category } k \text {, in } \\
\text { the period } t[\forall \mathrm{t} ; \forall \mathrm{u} ; \forall \mathrm{k} \in \mathrm{K}] \text {. }\end{array}$ \\
\hline \multicolumn{2}{|c|}{ Table 4 Other variables } \\
\hline Variable & Description \\
\hline $\begin{array}{l}\delta_{\mathrm{ukt}}^{+} \delta_{\mathrm{ukt}}^{-} \\
\in \mathbb{R}^{+}\end{array}$ & $\begin{array}{l}\text { Positive and negative discrepancies, respectively, between the preferable and the planned composition of the } \\
\text { academic staff in the category } k \text {, unit } u \text { and period } t[\forall \mathrm{t} ; \forall \mathrm{u} ; \forall \mathrm{k} \in \mathrm{K}] \text {. }\end{array}$ \\
\hline$\delta_{\mathrm{ut}} \in \mathbb{R}^{+}$ & $\begin{array}{l}\text { Maximum discrepancy (positive or negative), between the preferable and the planned composition of the } \\
\text { academic staff in all units in period } t\left(\text { i.e. } \delta_{\mathrm{ut}}=\max _{k}\left(\delta_{\mathrm{ukt}}^{+}, \delta_{\mathrm{ukt}}^{-}\right) \text {) }[\forall \mathrm{t}] \text {. }\right.\end{array}$ \\
\hline$\Delta_{t} \in \mathbb{R}^{+}$ & $\begin{array}{l}\text { Maximum discrepancy between the preferable and the planned composition of the academic staff }\left(\Delta_{t}=\right. \\
\left.\max _{u}\left(\delta_{t}\right)\right) \text {. }\end{array}$ \\
\hline
\end{tabular}

Model

$[M I N] z=\sum_{\forall u, t}\left[\sum_{\forall k}\left(c_{k t} \cdot w_{u k t}\right)+v_{t} \cdot A_{u t}\right]+c f \cdot \sum_{\forall u, k \in K, t}\left(\mathrm{w}_{\mathrm{ukt}}^{-}\right)+\sum_{\forall k \in K, u, t}\left[\lambda_{k t} \cdot\left(\delta_{u k t}^{+}+\delta_{u k t}^{-}\right)\right]+\sum_{\forall u, t} \mu_{t} \cdot \delta_{u t}+\omega \cdot$ $\sum_{\forall t} \Delta_{\mathrm{t}} \quad(1)$

Subject to

$\begin{array}{ll}\sum_{\forall k} w_{u k t} \cdot h_{k t}+A_{u t} \geq\left(1+\alpha_{u t}\right) \cdot C_{u t} & \forall u, t \\ w_{u k t}=w_{u k t-1}-L_{u k t}+\sum_{s \in \Gamma_{k}^{-}} Q_{u s k t}-\sum_{l \in \Gamma_{k}^{+}} Q_{u k l t}+w_{u k t}^{+}-w_{u k t}^{-} & \forall u, t ; \forall k \epsilon(K C \cup K P)\end{array}$

$w_{u k t}=w_{u k t}^{+}+\sum_{s \in \Gamma_{k}^{k}} Q_{u s k t}$

$\forall u, t ; \forall k \in K T$

$Q_{u s k t} \leq r_{u s k t} \cdot w_{u k, t-1}$

$\forall u, t ; \forall s \epsilon K \mid \Gamma_{s}^{+} \neq\{\varnothing\} ; \forall k \epsilon \Gamma_{s}^{+}$

$w_{u k t} \geq\left(L P_{k t} \cdot \sum_{\forall k} w_{u k t}\right)-\delta_{u k t}^{-}$

$\forall u, t ; \forall k \epsilon K$

$w_{u k t} \leq\left(U P_{k t} \cdot \sum_{\forall k} w_{u k t}\right)+\delta_{u k t}^{+}$

$\forall u, t ; \forall k \epsilon K$

$\delta_{u t} \geq \delta_{u k t}^{+}+\delta_{u k t}^{-}$

$\forall u, t ; \forall k \in K$

$\Delta_{\mathrm{t}} \geq \delta_{\mathrm{ut}}$

$\forall u, t$

$\sum_{\forall u}\left[\sum_{\forall k}\left(c_{k t} \cdot w_{u k t}\right)+v_{t} \cdot A_{u t}\right] \leq B_{t}$

$\forall t$

$w_{u k t}, A_{u t}, Q_{u k l t}, w_{u k t}^{+}, w_{u k t}^{-}, \delta_{u k t}^{-}, \delta_{u k t}^{+}, \delta_{u t}, \Delta_{\mathrm{t}} \geq 0$

$\forall u, t ; \forall k \epsilon K$ 
Equation (1) presents the objective function. The aim is to minimize the costs associated to: $i$ ) the salaries of the workers per each category $k$, unit $u$ and time $t\left(\sum_{\forall u, t}\left[\sum_{\forall k}\left(c_{k t} \cdot w_{u k t}\right)+v_{t} \cdot A_{u t}\right]\right)$; ii) penalties for hiring staff $\left(c f \cdot \sum_{\forall u, k \in K, t}\left(\mathrm{w}_{\mathrm{ukt}}^{-}\right)\right)$; iii) and those costs associated to discrepancies between the preferable and the planned composition in academic staff $\left(\sum_{\forall k \in K, u, t}\left[\lambda_{k t} \cdot\left(\delta_{u k t}^{+}+\delta_{u k t}^{-}\right)\right]+\sum_{\forall u, t} \mu_{t} \cdot \delta_{u t}+\omega \cdot \sum_{\forall t} \Delta_{t}\right)$. Equation (2) determines the minimum available capacity (teaching hours) considering the service level. Equations (3) and (3') balance the number of the staff members for each category, unit and period (note that equation (3') includes the fact that, given that temporary categories have been split into as many categories as years a person can belong to the category, nobody can stay more than one year in the same temporary category). As frequently, there is a limitation on the spots, an upper bound on the number of workers to be promoted is imposed in (4). Constraints regarding the preferable composition of the academic staff (between an upper and a lower bound) are included in equations (5) and (6). Constraints (7) and (8) lead calculate the maximum discrepancies within all categories and periods, to avoid, insofar as possible, that the discrepancy is concentrated in few categories or periods (assuming that it is preferable a regular distribution of the discrepancy). Constraint (9) limits the budget for salaries of the academic staff per period. Finally, constraint (10) imposes that the variables are non-negative.

There are universities that prioritize promotions over foreign contracting due to politics aiming to return the investment in personnel training. In order to represent these policies in the model, a binary variable $y_{\text {uskt }}$ is defined. This is an auxiliary variable for modelling the condition of prioritize the promotion of the current workers from the category $s$ to the category $k$ above hiring workers from the labour market, in the unit $u$ and the category $k$, in the period $t$. Introduction of binary variable $y_{\text {uskt }}$ permits to define constraints (11) to (13):

$y_{u s k t} \in\{0,1\}$

$Q_{u s k t} \geq r_{u s k t} \cdot w_{u k t}-r_{u s k t} \cdot\left(\frac{C_{u t} \cdot\left(1+\alpha_{u t}\right)}{h_{k t}}\right) \cdot y_{u s k t}-1$

$w_{u k t}^{+} \leq\left(\frac{C_{u t} \cdot\left(1+\alpha_{u t}\right)}{h_{k t}}\right) \cdot\left(1-y_{u s k t}\right)$

$$
\forall u, t ; \forall s \in K \mid \Gamma_{s}^{+} \neq\{\varnothing\} ; \forall k \epsilon \Gamma_{s}^{+}
$$$$
\forall u, t ; \forall s \in K \mid \Gamma_{s}^{+} \neq\{\varnothing\} ; \forall k \epsilon \Gamma_{s}^{+}
$$$$
\forall u, t ; \forall s \in K \mid \Gamma_{s}^{+} \neq\{\varnothing\} ; \forall k \epsilon \Gamma_{s}^{+}
$$

\section{Case study}

To test the goodness of the proposed model this has been applied to a real case, the Universitat Politècnica de Catalunya (UPC). The objective is to determine the workforce for each of the units and categories, taking into account not only economic factors, but also considering a preferable composition of the workforce.

It has been considered that normally in universities workforce is determined considering only economic criteria. Thus, the analysis of the results is based on the evaluation of the impact, as a decision criterion, of the achievement of a workforce according to a preferable composition and for the required service level. The following subsections present the main characteristics of the UPC, the data used and the obtained results.

\subsection{Description of the UPC case}

The Universitat Politècnica de Catalunya (UPC) was created in 1971 and is one of the most important technical universities in Spain. This public university offers 68 different bachelors and masters basically in the field of engineering serving more than 30,000 students distributed in 23 different centers (schools and faculties). The academic workforce is around 3,000 people and there are 42 departments, i.e. units.

The UPC concerns two types of categories for workforce: temporary and permanent. Regarding temporary categories $(K T)$, it is mandatory for a member of the staff to progress to a higher category once a certain period of time is completed (otherwise the worker loses his or her job position). In these categories work contracts are annually renewed and workers are in a training period, so their capacity (teaching hours) is low in comparison with the workers in permanent categories. Regarding staff in permanent categories, the workers have the same teaching capacity and can follow two different pathways in their careers: contractual $(K C)$ and public/tenure $(K P)$ pathways. The main difference between $K C$ and $K P$ categories are that personnel in contractual pathway can be fired (provided that economic compensation is paid) and that the progression in public pathway $(K P)$ is harder than in contractual path because of the difficulty in reaching the required merits and the availability of a new spot. Workers can switch between pathways by promotion. 
Currently, workforce is organized in $k=15$ categories, of which 8 are temporary categories (i.e. the subset $K T$ ), and the rest are permanent categories. Within this last group, 3 of them correspond to subset $K C$ (workers with a permanent contract), and finally 4 categories belong to subset $K P$ (workers with a public/tenure contract). Figure 1 includes a chart with the evolution of academic staff through the different categories in UPC.

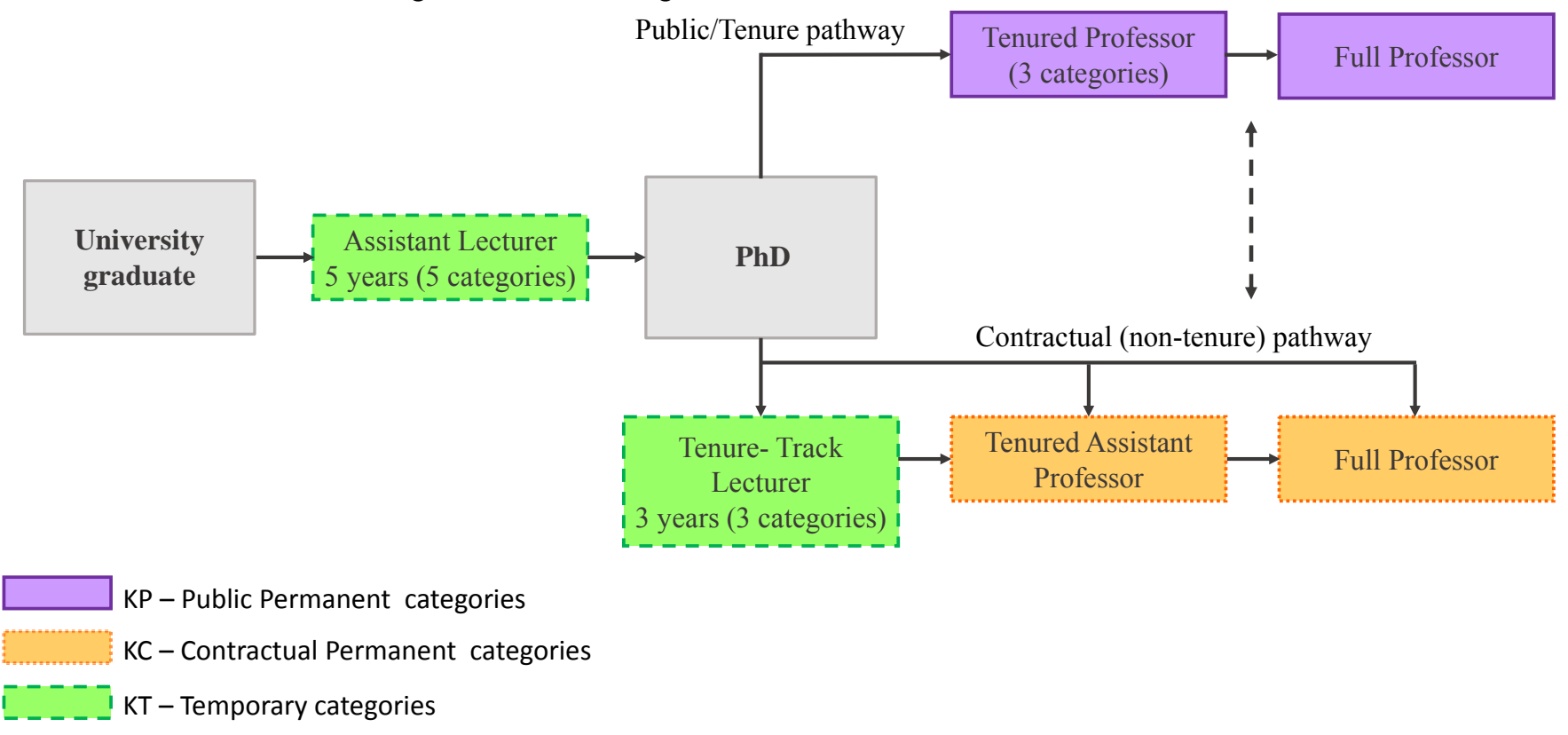

Figure 1. Categories in the UPC and the evolution of the academic career.

The preferable composition structure of the university has been obtained from a poll on university management addressed to a selected group of relevant academics. The results yield a set of pyramids based on academic research objectives and regulatory framework in universities. Given this, the preferable pyramid for planning the composition has been obtained from those values that most resembled each other in the organization (this explains why the preferable values are not integer, which may seem strange at a first sight). The preferable composition resulting from the poll and the current or initial composition are depicted in Figure 1. As it can be noted, the proportion of university workforce in permanent categories within $K P$ exceeds $60 \%$; as it can be seen in Figure 1, this set includes four categories (three for tenured professors and one for full professor). The rest of the academic staff is distributed amongst permanent categories within $K C$ (nearly $20 \%$ ) and temporary categories within $K T$ (around 18\%). The remarkable weight of total workforce within $K P$ configures a highly resilient institution against changes in pyramid organization structure, since most of the workers cannot be fired and the only way to adjust their number is the time (with the layoffs) and/or the promotions. This characteristic resilience difficulties achieving the preferable composition presented in Figure 2, in which the share of temporary categories should increase up to $41 \%$ of the total workforce; as a consequence the share of the permanent categories within $K C$ and $K P$ will be reduced. 


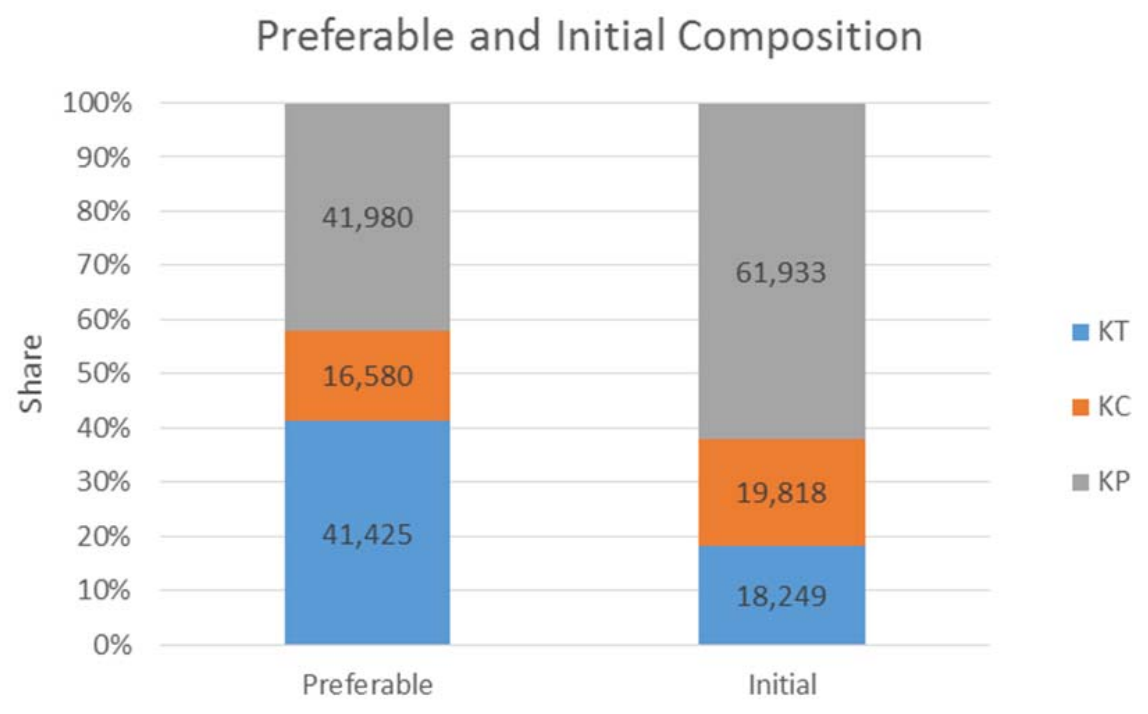

Figure 2. Comparison between preferable and initial academic staff composition of the UPC.

For solving the model and addressing the specificities of the UPC, several data are needed on economic costs, regulations, promotions and retirements, among other factors. These aspects are summarized in the following:

- The costs associated to the staff for the different categories $\left(c_{k t}, v_{t}\right)$, have been considered constant for any time $t$ and have been estimated from the university public information (UPC, 2014).

- In the same way, the teaching hours of the workers $h_{k t}$ for each category is considered constant according to the current law (UPC, 2014).

- The required capacity (demand) for each unit or department throughout the time horizon $C_{u t}$ is assumed constant. The demand has been deduced from the number of students enrolled in the subjects given by each unit.

- The expected personnel cuts $L_{k t}$ and also the possible promotions $r_{u s k t}$ are estimated from historic data (ANECA, 2014; AQU, 2014; Ministry, 2014). This approach is also adopted for estimating the minimum required excess of capacity for each unit $\alpha_{u t}$. According to (UPC, 2014), an excess capacity of about $25 \%$ can be considered adequate. This excess capacity compensates the reduction in the capacity of workers due to the dedication to academic management tasks.

- $\quad$ The sets of categories $\Gamma_{k}^{+}$and $\Gamma_{k}^{-}$derive from the current laws to be applied to the UPC (ANECA, 2014; AQU, 2014; Ministry, 2014).

- The budget for each time is considered constant $B_{t}$ and it is also estimated from the information published by the university (UPC, 2014).

- The university policies establish that the maximum length of time (consecutive years) a professor can be rector is eight years (two consecutive four year periods). Also, eight years is the required time for achieving a tenure position. Hence, it seems appropriate to consider an eight-year horizon for the UPC staff planning.

Note that the required capacity (demand) and the budget (also the costs) have been intended constant in order to better evaluate the performance of the model avoiding the effect of the variability in the aforementioned factors.

All these data would allow the execution of the proposed model, but just considering economic aspects, so avoiding those aspects referred to the preferable composition of the workforce. In the following, those parameters for including the preferable composition criteria are introduced.

In order to achieve the preferable workforce composition, and for modelling purposes, and as previously stated in Section 3, $U P_{k t}$ and $L P_{k t}$ were introduced as preferable bounds for the proportion of each category in the academic staff. In the current case, parameters $U P_{k t}$ and $L P_{k t}$ permit a deviation of up to $\pm 25 \%$ for the percentage of each category within $K T$, $K C$ and $K P$ taking into account the preferable composition shown in Figure 2.

In order to include the personnel cost and the deviations from a preferable staff composition in a single objective function, the latter have been penalized in an economic term. Penalty $\lambda_{k t}$ is the annual salary per each category and worker, whilst penalty $\mu_{t}$ is computed as a proportion (around $5 \%$ ) of the annual average budget of a department and $\omega$, as a proportion (around 1\%) of the annual budget for the entire university. The aforementioned penalties have been considered constant throughout the considered time horizon.

For evaluating the capacity, it is worth noting that only tasks related to teaching are considered. Nevertheless, the capacity of a worker can be minored depending on the attributions of other duties (e.g. research and management tasks) apart 
from teaching. Thus, the staff requirements are calculated according to the capacity in number of hours per worker and category. The remaining tasks are taken into account in an indirect way according to the composition of the academic staff.

Finally, it is worth to remark that staff promotions are prioritized over foreign contracting, as established by constraints (11) to (13).

\subsection{Results and analysis}

The following results show the performance of the proposed model for the optimization of the workforce composition of the UPC considering a time horizon of 8 years. The model formulated in Section 3 was solved in IBM ILOG CPLEX Optimization Studio software (version 12.2), with the variables, constraints and execution time summarized in Table 5.

Table 5 The CPLEX Optimization Studio solution report

\begin{tabular}{ccccc}
\hline Real variables & Integer variables & Binary variables & Constraints & Execution time \\
\hline 14,197 & 20,370 & 1,344 & 43,268 & $1000 \mathrm{~s}$ \\
\hline
\end{tabular}

The performance of the model is evaluated by defining different metrics. Metric $R C_{u k t}$ is the proportion of staff over the whole staff of the unit $u$ at period $t$ belonging to category $k$ (resulting from the solution of the model), computed as

$R C_{u k t}=\frac{w_{u k t}}{\sum_{k=1}^{K} w_{u k t}} \quad \forall u, k, t$

Let $P C_{k}$ the preferable weight of category $k$ in the university workforce composition. Using $R C_{u k t}$, the Global Discrepancy $G D_{u t}$ is computed by the addition of the discrepancy, for category $k$, between $P C_{k}$ and the workforce obtained per each period $t$ and unit $u$ :

$G D_{u t}=\sum_{k=1}^{K}\left|P C_{k}-R C_{u k t}\right|$

$\forall u, t$

Since the index $G D_{u t}$ accumulates the aforementioned discrepancy associated to each category, the obtained value can exceed 1 p.u. (i.e 100\%).

The metrics $R C_{u k t}$ and $G D_{u t}$ are clearly related to equations (5) and (6) of the model.

Table 6 shows $\overline{G D_{t}}=\sum_{u=1}^{U} G D_{u t}$, the average $G D_{u t}$ for each period $t$, and also the maximum discrepancy (i.e., $\delta_{\mathrm{ut}}$ variables). The comparison of the two consecutive values of $\overline{G D_{t}}$ throughout the considered temporal horizon is also depicted. It is clear from Table 6 that the global discrepancy is being progressively reduced throughout the time horizon, from a value of 0.974 down to 0.329 . The major reduction in global discrepancy is in the first periods of the considered time horizon. In the rest of the periods the improvement is relatively small, since the staff composition gets closer to the preferable one.

Table 6 Average Global Discrepancy $\overline{\boldsymbol{G D}}$ and Decreasing of Average Global Discrepancy $\overline{\boldsymbol{G} \boldsymbol{D}_{\boldsymbol{t}}}$, comparing two consecutive years.

\begin{tabular}{l|ccccccccc}
\hline $\mathbf{t}$ & $\mathbf{0}$ & $\mathbf{1}$ & $\mathbf{2}$ & $\mathbf{3}$ & $\mathbf{4}$ & $\mathbf{5}$ & $\mathbf{6}$ & $\mathbf{7}$ & $\mathbf{8}$ \\
\hline$\overline{\boldsymbol{G D}}$ & 0.974 & 0.641 & 0.541 & 0.433 & 0.4 & 0.362 & 0.345 & 0.335 & 0.329 \\
$\overline{\boldsymbol{G} \boldsymbol{D}_{\boldsymbol{t}}}-\overline{\boldsymbol{G D}} \boldsymbol{t + 1}$ & 0.333 & 0.1 & 0.108 & 0.033 & 0.038 & 0.017 & 0.01 & 0.006 & \\
\hline
\end{tabular}

Figure 3 plots $\overline{G D_{t}}$, the average index $G D_{u t}$ for the 42 units, as well as the maximum and minimum values between $\mathrm{t}=0$ and $\mathrm{t}=8$. As it can be observed, the proposed procedure for the strategic capacity planning reduces progressively along the time horizon the discrepancy between preferable and planned workforce compositions. Most of the changes are applied in the early years of the horizon (note that this also means that from the results point of view an eight-year horizon is appropriate). The discrepancy has been reduced for all 42 units, without any exception. 

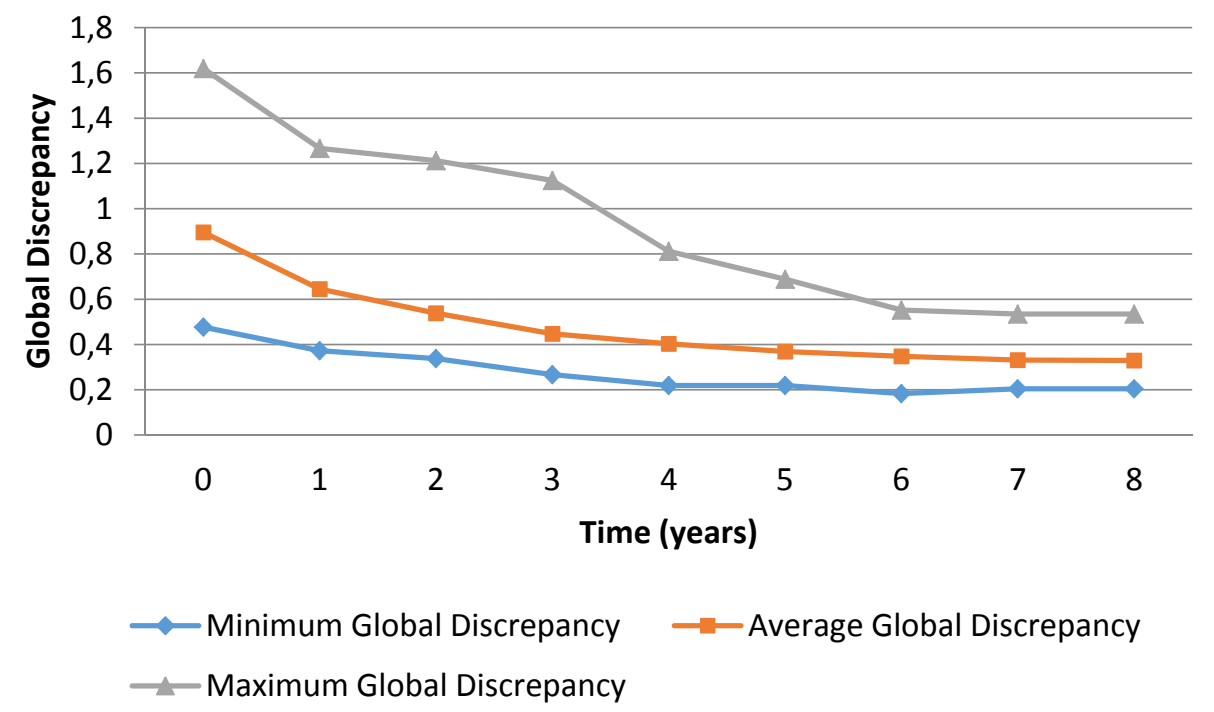

Figure 3. Evolution of the global discrepancy $\boldsymbol{G D}_{\boldsymbol{u t}}$ (mean, maximum and minimum values) in a time horizon of 8 years.

As a result of the optimization procedure, the final workforce composition is much similar to the preferable composition than the initial one, as plotted in Figure 4 (i). As shown, categories within subset $K C$ hold minor changes as they were initially closed to the preferable composition. On the other hand, categories within $K T$ and $K P$ have been substantially modified.

Further, and as shown in Figure 4 (ii), it is important to remark that the optimization results lead a substantial reduction in the total number of workers of the university, which also shows that the academic workforce was too oversized.
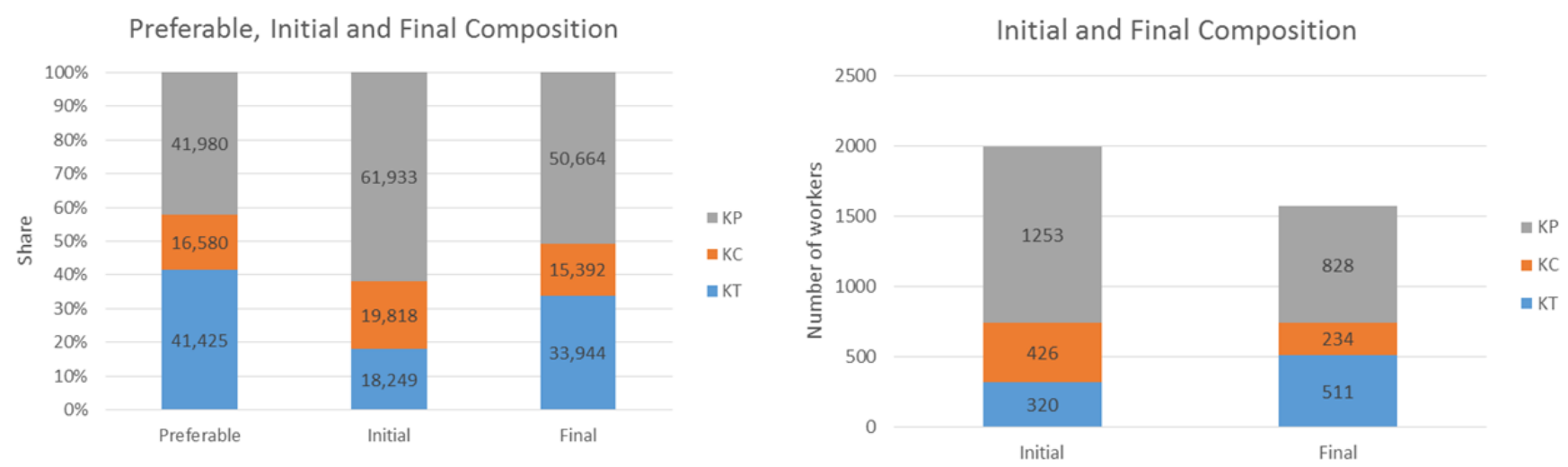

Figure 4.Comparison between the preferable, the initial and the final compositions and the initial and the final number of academic workers in the UPC.

Complementing the performance evaluation of the optimization procedure, the following results give details for the subsets of categories $K T, K C$ and $K P$. Each one of them is influenced by the singularities of that particular subset affecting strategic decisions, so this incentivizes separate studies which results are graphically plotted in Figures 5, 6 and 7. These figures present the Global Discrepancy $\boldsymbol{G D}_{\boldsymbol{u t}}$ for each subset of categories and for each unit and time, in order to evaluate the evolution of the index influenced by the specificities of each subset. The mean results are given in Table 7 and Table 8 . 


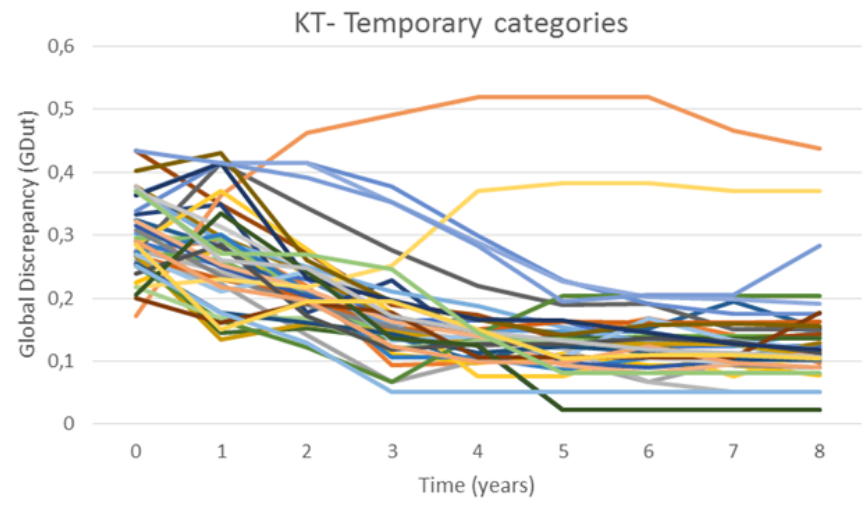

Figure5. Evolution of the Global Discrepancy $\boldsymbol{G} \boldsymbol{D}_{\boldsymbol{u}}$ in subset $\boldsymbol{K} \boldsymbol{T}$ per unit and period.

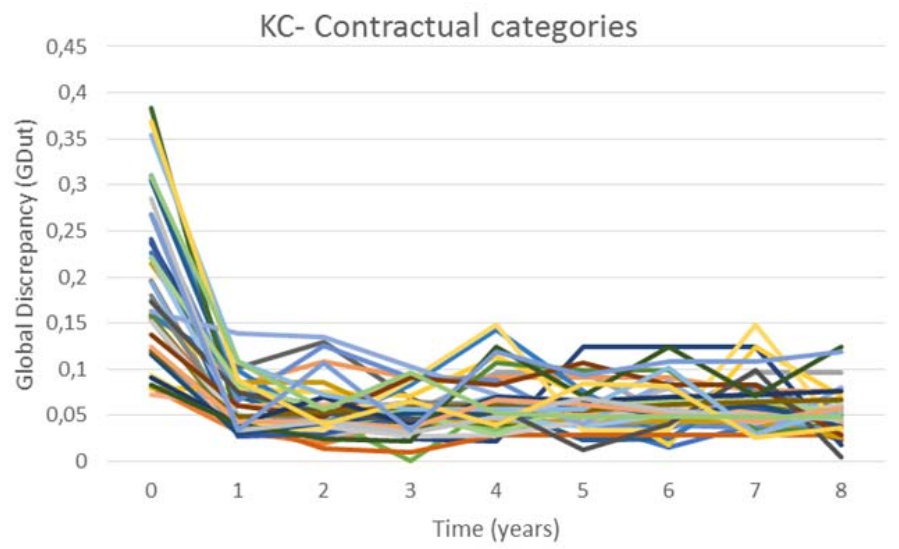

Figure 6. Evolution of the Global Discrepancy $\boldsymbol{G D}_{\boldsymbol{u t}}$ in subset $K C$ per unit and period.

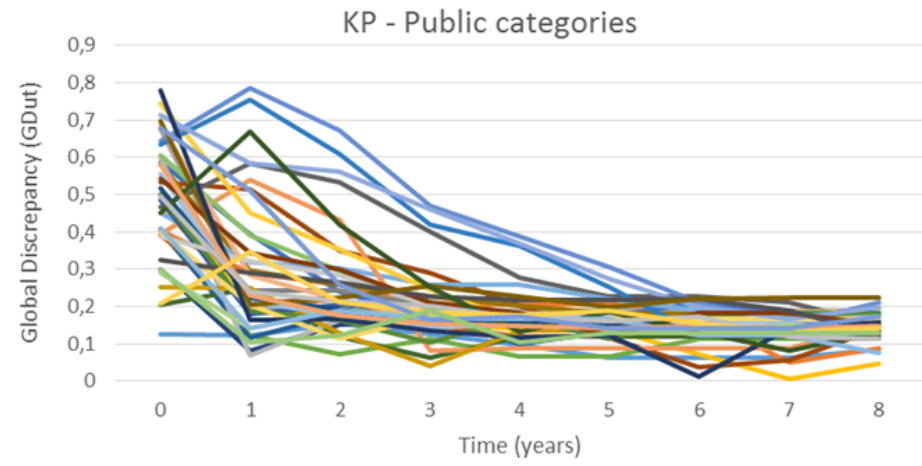

Figure 7. Evolution of the Global Discrepancy $\boldsymbol{G} \boldsymbol{D}_{\boldsymbol{u}}$ in subset $\boldsymbol{K P}$ per unit and period.

Table 7. Average Global Discrepancy $\overline{\boldsymbol{G D}}$ for subsets $\boldsymbol{K T}, \boldsymbol{K C}$ and $\boldsymbol{K P}$ in a time horizon of 8 years.

\begin{tabular}{c|ccccccccc}
\hline $\boldsymbol{t}$ & $\mathbf{0}$ & $\mathbf{1}$ & $\mathbf{2}$ & $\mathbf{3}$ & $\mathbf{4}$ & $\mathbf{5}$ & $\mathbf{6}$ & $\mathbf{7}$ & $\mathbf{8}$ \\
\hline Subset $\boldsymbol{K T}$ & 0.297 & 0.276 & 0.230 & 0.179 & 0.159 & 0.142 & 0.140 & 0.133 & 0.133 \\
Subset $\boldsymbol{K C}$ & 0.192 & 0.061 & 0.055 & 0.053 & 0.065 & 0.060 & 0.059 & 0.061 & 0.052 \\
Subset $\boldsymbol{K} \boldsymbol{P}$ & 0.485 & 0.304 & 0.256 & 0.201 & 0.176 & 0.160 & 0.146 & 0.141 & 0.144 \\
\hline
\end{tabular}


Table 8. Difference of Average Global Discrepancy $\overline{\overline{G D_{t}}-\overline{G D_{t+1}}}$, for subsets $K T, K C$ and $\boldsymbol{K P}$ in a time horizon of 8 years.

\begin{tabular}{c|cccccccc}
\hline $\boldsymbol{t}$ & $\mathbf{0}$ & $\mathbf{1}$ & $\mathbf{2}$ & $\mathbf{3}$ & $\mathbf{4}$ & $\mathbf{5}$ & $\mathbf{6}$ & $\mathbf{7}$ \\
\hline Subset $\boldsymbol{K} \boldsymbol{T}$ & 0.021 & 0.046 & 0.051 & 0.020 & 0.017 & 0.002 & 0.007 & 0.000 \\
Subset $\boldsymbol{K C}$ & 0.131 & 0.006 & 0.002 & -0.012 & 0.005 & 0.001 & -0.002 & 0.009 \\
Subset $\boldsymbol{K P}$ & 0.181 & 0.048 & 0.055 & 0.025 & 0.016 & 0.014 & 0.005 & -0.003 \\
\hline
\end{tabular}

Figure 5 plots index $\boldsymbol{G} \boldsymbol{D}_{\boldsymbol{u}}$ for the subset $\boldsymbol{K} \boldsymbol{T}$ (the temporary academic staff). As a figure of merit, the discrepancy $\boldsymbol{G} \boldsymbol{D}_{\boldsymbol{u}}$ has been reduced for the $95 \%$ of the units considering categories in $\boldsymbol{K T}$. As a reminder, employment contracts for workers in categories within $\boldsymbol{K T}$ are renewed annually; so, this permits high flexibility while determining workforce composition -note the high variability of $\boldsymbol{G} \boldsymbol{D}_{\boldsymbol{u}}$ in Figure 5, also numerically summarized in the first row of Table 8-. Further, and bearing in mind that most workers in these categories are in training periods, they offer reduced capacity and economic yield. These factors lead strategic decisions concerning subset $\boldsymbol{K T}$ subordinated to some extent to those decisions taken for workforce composition of permanent categories. The effects of such subordination can be also observed in Figure 5, focusing on the increasing Global Discrepancy $\boldsymbol{G D}_{\boldsymbol{u t}}$ for subset $K T$ in some units. Capacity for these units surplus the demand and workers are mostly in categories within $K P$, so they cannot be fired. As a result, workforce composition is very constrained and it is only driven by promotions and layoffs. Given that contracts are annually renewed for $K T$ and penalizations associated to a preferable composition are lower than for categories within $K P$ and $K C$, it seems reasonable to expect minor adjustments for $K T$ versus the rest of the categories.

Figure 6 plots the index $\boldsymbol{G} \boldsymbol{D}_{\boldsymbol{u}}$ for the subset $\boldsymbol{K} \boldsymbol{C}$ (permanent staff that can be fired with economic penalty). As it is shown, most of the strategic decisions are taken in the very beginning of the considered time horizon. From this point on, the workforce composition becomes almost steady. As a result, the discrepancy $\boldsymbol{G D}_{\boldsymbol{u}}$ has been reduced in $97 \%$ of the units considering $\boldsymbol{K} \boldsymbol{C}$. Adjustments are influenced by the fact that strategic decisions within $\boldsymbol{K} \boldsymbol{C}$ are subjected to penalties due to discrepancies between preferable and actual composition as well as those associated to the cost of firing. Note that workers in $\boldsymbol{K} \boldsymbol{C}$ holds permanent contracts. The second row of Table 7 and Table 8 supports graphical results on categories within $\boldsymbol{K} \boldsymbol{C}$.

Finally, Figure 7 presents the index $\boldsymbol{G} \boldsymbol{D}_{\boldsymbol{u}}$ for the subset $\boldsymbol{K P}$ (permanent staff that cannot be fired) and the third row of Table 7 and Table 8 gives the associated values $\overline{\boldsymbol{G D}_{\boldsymbol{t}}}$ and its temporal variation. The workforce composition in $\boldsymbol{K P}$ for all units has been improved, as at the time horizon it results closer to the preferable in comparison to the initial. Opposite to the case of subset $\boldsymbol{K} \boldsymbol{C}$, strategic decisions towards preferable composition are not concentrated at the very beginning of the horizon, but they are distributed throughout most of the considered time. This is because strategic decisions are restricted by the fact that workers hold permanent contracts and cannot be fired. If the weight of these categories at the beginning is too high (compared to the preferable one) as in this case, the managers should wait for the worker's promotion and the scheduled retirements.

\section{Computational study: performance of the model and managerial insights}

The previous sections introduce the problem of the strategic staff planning in universities, propose a model and apply it to a real case. Complementary, this section aims to prove the performance of the model under different scenarios considering the university size as well as to give some managerial insights according to the variation of some input data.

\subsection{Performance of the model}

This section presents the performance of the model under different university sizes. To do so, a set of experiments have been designed. Each one considers universities with different number of departments or units, as well as different number of categories. In particular, the number of departments is $|U|=\{20,60,100\}$, while the number of categories is $|K|=\{5,10,15\}$, altogether affecting the size and complexity of workforce structure. These assumptions are translated into 9 different scenarios for optimization. The model is, in turn, executed 10 times for each scenario varying input data as the budget and parameters $U P_{k t}$ and $L P_{k t}$ (which correspond to the preferable bounds for the proportion of academic staff that belongs to the category $k$ in the period $t$, see Table 2). The set of periods in the horizon are $T=10$ in this part of the study. A total execution time of 10,000 seconds was given to solve each instance, whose amount of time was reached for all the experiments.

A synthetic view of the obtained results is presented in Table 9: for each of the 9 scenarios, the minimum, average and maximum gap given by the software at the end of the execution time and the minimum, average and maximum time needed for achieving the given final solution. 
Table 9. Computational results (gap and time to obtain the final solution) for the model performance in the 9 scenarios.

\begin{tabular}{c|cc|ccc|ccc}
\cline { 3 - 8 } \multicolumn{2}{c}{} & \multicolumn{3}{c|}{ Gap (\%) } & \multicolumn{3}{c}{ Time (minutes) } \\
\hline Scenario & $|\mathbf{U}|$ & $|\mathbf{K}|$ & Min & Mean & Max & Min & Mean & Max \\
\hline 1 & 20 & 5 & 0 & 0 & 0 & 13 & 13 & 13 \\
2 & 20 & 10 & 1.17 & 1.20 & 1.21 & 39 & 40 & 42 \\
3 & 20 & 15 & 1.05 & 1.06 & 1.07 & 69 & 69 & 75 \\
\hline 4 & 60 & 5 & 0.58 & 0.64 & 0.65 & 32 & 33 & 36 \\
5 & 60 & 10 & 1.43 & 1.45 & 1.46 & 34 & 46 & 48 \\
6 & 60 & 15 & 1.71 & 1.76 & 1.77 & 95 & 96 & 98 \\
\hline 7 & 100 & 5 & 0.86 & 0.90 & 1.02 & 39 & 41 & 41 \\
8 & 100 & 10 & 1.86 & 2.04 & 2.06 & 120 & 127 & 131 \\
9 & 100 & 15 & 1.74 & 2.03 & 2.08 & 144 & 155 & 167 \\
\hline
\end{tabular}

As can be noted, the maximum gap to the optimal solution has been bounded to $2.08 \%$, which can be considered very good taking into account that a long term and strategic problem is being solved. The time needed to reach an admissible gap and the gap magnitude both increase with the considered number of units and categories but, overall, both can be considered small enough.

\subsection{Managerial insights}

This section aims to study the model sensitivity under variations of different characteristic parameters. In particular, the analyses are concentrated in three main aspects: workforce structure, worker capacity per subset of categories and personnel costs. For each issue, several scenarios are studied. The scenario \#0 is the basic case, i.e. that already considered in Section 4. The total number of computational experiments carried out is 11 . The obtained results are below presented according to each input data.

\subsubsection{Workforce structure}

The number of temporary categories $K T$, public permanent categories $K P$ and contractual permanent categories $K C$ has been varied, which gives different ratios between temporary and permanent contracts. The total number of categories is always 15. There are 3 new scenarios. In scenario 1 the number of categories within $K C$ is left constant and there are less temporary categories. Scenario 2 has the same number of categories within $K P$ and proposes that the number of categories within $K C$ is increased. Scenario 3 suggests a different number of categories within $K C$ and $K P$, with same initial temporary categories.

The summary of the main results for the considered scenarios at the end of the considered time horizon $(t=8)$ are presented in Table 10: the personnel costs, the number of workers for groups of categories and the Global Discrepancy $\overline{G D_{8}}$.

Table 10 Sensitivity analysis concerning workforce structure in $\boldsymbol{t}=\mathbf{8}$ for the different scenarios.

\begin{tabular}{|c|c|c|c|c|c|c|c|c|c|}
\hline Scenario & $K T$ & $K C$ & $K P$ & $\begin{array}{l}\text { Personnel } \\
\text { costs }\end{array}$ & $\begin{array}{c}\Sigma_{u, k} \\
w_{u k 8} \\
\forall u, k \epsilon K T\end{array}$ & $\begin{array}{c}\Sigma_{u, k} \\
w_{u k 8} \\
\forall u, k \in K C\end{array}$ & $\begin{array}{c}\Sigma_{u, k} \\
w_{u k 8} \\
\forall u, k \in K P\end{array}$ & $\begin{array}{c}\sum_{u, k} \\
w_{u k 8} \forall u, k\end{array}$ & $\overline{G D_{8}}$ \\
\hline$\# 0$ & 8 & 3 & 4 & 98990991 & 462 & 254 & 844 & 1560 & 0.329 \\
\hline$\# 1$ & 6 & 3 & 6 & 99974447 & 416 & 249 & 941 & 1606 & 0.235 \\
\hline$\# 2$ & 6 & 5 & 4 & 99824311 & 415 & 390 & 800 & 1605 & 0.233 \\
\hline$\# 3$ & 8 & 5 & 2 & 97809823 & 454 & 255 & 824 & 1533 & 0.337 \\
\hline
\end{tabular}

The lowest difference in personnel costs, number of workers per subset of categories and Global Discrepancy in comparison to scenario 0 , is obtained in scenario 3. The greater number of categories within $K C$ and $K T$ provides the system with flexibility for firing workers (as a reminder, workers in $K P$ cannot be fired) and the university workforce barely diminishes (from 1560 to 1533 workers) and, as a consequence, the total personnel costs.

Major differences can be observed comparing scenarios with 8 temporary categories (scenarios 0 and 3 ) to the ones with only 6 ones. If the number of temporary categories decreases (scenarios 1 and 2) decisions must be taken in a more rigid environment than in scenario 0 . This rigidity comes from the fact that more workers' firing is now subjected to an economic penalization and they cannot be fired if they are included in permanent categories $K P$. As a result, the total number of workers (and the total personnel costs) is greater in scenarios 1 and 2 than in the rest, because of the resilience of the system to reduce the number of workers in permanent categories. 


\subsubsection{Workforce capacity (teaching hours)}

Workforce capacity $h_{k t}$ is a parameter that directly affects the number of workers in each of the categories of the university, in order to fulfil demand requirements. Intuitively, one can expect that the lower the ratio $c_{k t} / h_{k t}$ (i.e. the specific cost per capacity unit for a worker in the category $k$ and period $t$ ), the higher the number of workers to be hired towards the cost minimization. This is successfully predicted by the model, as presented in Table 11.

In the three new scenarios, the number of teaching hours corresponding to one of the group of categories has been doubled. As it can be noted, comparing the results for scenarios 1 to 3 versus scenario 0 , an increment in the capacity in all of the category subsets is clearly translated in a reduction of personnel costs for the university. It is interesting to note that if the capacity of workers within $K T$ is doubled (scenario 1) the hiring of such workers is favoured and thus the achievement of the preferable workforce composition (as a reminder, $41 \%$ of university workforce should be sustained by workers in categories within $K T$ in this case, see Figure 2). This is translated in a reduction of the Global discrepancy compared to that for scenario 0 . On the other hand, the higher capacity of workers in permanent categories (scenarios 2 and 3) compromises the achievement of the ideal workforce composition. Since these categories were initially oversized, an increment in workers capacity does not facilitate the downsizing.

Table 11 Sensitivity analysis concerning workforce capacity in $\boldsymbol{t}=\mathbf{8}$ for the different scenarios.

\begin{tabular}{|c|c|c|c|c|c|c|c|c|c|}
\hline Scenario & $h_{K T}$ & $h_{K C}$ & $h_{K P}$ & $\begin{array}{l}\text { Personnel } \\
\text { costs }\end{array}$ & $\begin{array}{c}\Sigma_{u, k} \\
w_{u k 8} \\
\forall u, k \in K T\end{array}$ & $\begin{array}{c}\Sigma_{u, k} \\
w_{u k 8} \\
\forall u, k \in K C\end{array}$ & $\begin{array}{c}\Sigma_{u, k} \\
w_{u k 8} \\
\forall \boldsymbol{u}, \boldsymbol{k} \in \boldsymbol{K} P\end{array}$ & $\begin{array}{c}\Sigma_{u, k} \\
w_{u k 8} \forall u, k\end{array}$ & $\overline{G D_{8}}$ \\
\hline$\# 0$ & 1 & 1 & 1 & 98990991 & 462 & 254 & 844 & 1560 & 0.329 \\
\hline$\# 1$ & 2 & 1 & 1 & 88467242 & 579 & 223 & 675 & 1468 & 0.282 \\
\hline$\# 2$ & 1 & 2 & 1 & 85411902 & 404 & 245 & 688 & 1337 & 0.332 \\
\hline$\# 3$ & 1 & 1 & 2 & 74129503 & 304 & 148 & 660 & 1152 & 0.408 \\
\hline
\end{tabular}

\subsubsection{Workforce cost}

Finally, variations in workforce cost $c_{k t}$ are studied through five new scenarios, in which the cost per worker is increased for one or two of the subsets of categories respect to the scenario 0 . As presented in Table 12, results do not provide a very clear picture of the effect neither in workforce composition nor in total personnel costs for the university. However, comparing scenarios 1 to 3 versus the scenario 0 , it is remarkable that an increment in the salary for workers within a particular subset of categories is associated to a reduction in the number of workers in that subset. For instance, in the base case categories within $K T$ hold 462 workers, whose number is reduced to 435 in scenario 1; it is also the minimum for workers within KT compared to the rest of scenarios. Finally, if the salary for workers within permanent categories increases, but not for temporary ones (i.e. scenario 5), the number of workers within $K T$ is greater than in scenario 0 and the number of workers within $K T$ and $K P$ is reduced.

Table 12 Sensitivity analysis concerning workforce $\operatorname{cost}$ in $\boldsymbol{t}=\mathbf{8}$ for the different scenarios.

\begin{tabular}{|c|c|c|c|c|c|c|c|c|c|}
\hline Scenario & $c_{K T}$ & $c_{K C}$ & $c_{K P}$ & $\begin{array}{l}\text { Personnel } \\
\text { costs }\end{array}$ & $\begin{array}{c}\Sigma_{u, k} \\
w_{u k 8} \\
\forall u, k \in K T\end{array}$ & $\begin{array}{c}\Sigma_{u, k} \\
w_{u k 8} \\
\forall u, k \epsilon K C\end{array}$ & $\begin{array}{c}\Sigma_{u, k} \\
w_{u k 8} \\
\forall u, k \epsilon K P\end{array}$ & $\begin{array}{c}\Sigma_{u, k} \\
w_{u k 8} \forall \boldsymbol{u}, k\end{array}$ & $\overline{G D_{8}}$ \\
\hline$\# 0$ & 1 & 1 & 1 & 98990991 & 462 & 254 & 844 & 1560 & 0.329 \\
\hline \#1 & 1,25 & 1 & 1 & 102209470 & 435 & 259 & 850 & 1544 & 0.339 \\
\hline \#2 & 1 & 1,25 & 1 & 102635740 & 465 & 230 & 863 & 1558 & 0.331 \\
\hline \#3 & 1 & 1 & 1,25 & 113299060 & 480 & 262 & 832 & 1574 & 0.321 \\
\hline$\# 4$ & 1,25 & 1,25 & 1 & 105962650 & 443 & 237 & 865 & 1545 & 0.341 \\
\hline$\# 5$ & 1 & 1,25 & 1,25 & 117313190 & 487 & 251 & 837 & 1575 & 0.316 \\
\hline
\end{tabular}

\section{Conclusions and future research}

This work presents a mixed linear mathematical programming model for determining the size and composition of the academic staff of public universities under a long term planning horizon and taking into account the category structure and a 
preferable composition, while minimizing the associated costs. The problem, which is relevant and very important for the performance of any public university, is too difficult to be solved without an adequate and formalised procedure and powerful tools and techniques (as MILP is). The particular case of the Universitat Politècnica de Catalunya (UPC) has been chosen to apply the model to a real case. The designed model successes in obtaining a close composition to a preferable one taking into account constraints associated to budget and required service level. In particular, the Global Discrepancy, which considers the preferable workforce composition, has been reduced up to $95 \%$ for temporary categories, $97 \%$ for permanent (non-public) categories and $100 \%$ for permanent public categories. Also, the model is tested in a wide experiment to obtain both computational and managerial insights.

The main benefits of the proposed model are that it can be used to effectively and efficiently adjust the workforce to the requirements, for each unit (e.g., department), avoiding an excessive oversizing and that helps obtaining the decisions on hiring, dismissals and promotions that make the staff composition (pyramid) become similar to the desired one, without increasing the staff costs and taking into account the regulations (career pathway) and budget constraints.

The model can be applied to most real universities since all them have similar categories' structures. Of course, for some cases the results of the model can be better than for others. For example, if the initial staff was composed mainly on permanent staff, the flexibility to achieve different compositions would be very limited and, even though the model could be still used for staff decisions, the results would not be very good in terms of discrepancy between desired and obtained staff composition. Anyway, note that this is not a limitation of the model but a limitation due to a particular university situation.

The proposed planning procedure, based on a MILP model, fills an existing research and practical gap since, to the best of our knowledge, there are no formalised procedures for planning the staff considering the career pathway (promotions between categories) and other criteria than the purely economic ones. The computational experiment also demonstrates that using MILP for strategic decisions (which usually involve a high number of binary variables) is possible with the software and hardware technology available nowadays.

On the other hand, the main limitations of the model are the following: first, as normally happens with strategic planning procedures, some data and decisions are considered in an aggregate way (in this case, workers are not treated individually); even though this does not invalidate the results, it could happen that the results were not fully accurate (a detailed analysis should be done); and second, a proportion of people from one category that can pass to an upper category has been taken as a data, considering its average value. In reality the considered average proportion is a probability so it could happen that some decisions on promotions given by the model could not be applied in reality because less people than the expected had acquired the merits to be promoted. For very small departments, this could mean a significant loss of accuracy.

As it can be seen from the results of the experiments, achieving a composition similar to the preferable one is not an easy and fast thing. To guarantee a bit of stability in the university staff decisions, it is advisable that the preferable composition be somehow agreed by the university community, and not only by its government (the rector and his/her team).

The main features of the model could be applied to other organizations that may have different evaluation criteria and structure (e.g., consultancies in which workers may be classified by other criteria rather that unit and category or the objective in a private firm is different than in a public university). With the aim of widening the applicability of the proposed model, the problem specification adopted is applicable to any KIO. The proposed general specification can be adapted taking into account the particularities of each type of organization, for instance, possible differences in the structure (in universities, research centres...).

Further, five research lines can be derived from this study. First, the performance and/or results of the model depending on some parameters can be further analysed; for example, how the initial and the desired composition affect the values and evolution of the global discrepancy. Second, and with the aim of overcoming one of its main limitations, the model could be modified to consider the uncertainty of some data (as the demand, the promoting ratios, etc.). Third, the proportion of people that can be promoted to an upper category can be included as a variable, considering that this depends partially on the strategy of the university (the current model would become a non-linear model that should be linearized). For example, if more funding is given to research and this has a great weight in the merits for promotion, people can improve their CV and reach more easily a higher category. Fourth, the model can be used to evaluate the impact of some strategic decisions: allowing or not the firing of temporary workers; modifying the required capacity by eliminating or adding courses, changing the size of the groups... The sizes are related to the different management models adopted for the university (for example, the Oxford model in which there are few lessons with a very high number of students and given by high category professors and the several students groups followed by academic in lower categories). And fifth, the model could be adapted to other organizations as, for example, business consultancies.

\section{Acknowledgements}

The authors are grateful to the anonymous referees who provided helpful comments on this paper. Supported by the Spanish Ministerio de Economia y Competitividad (project DPI2010-15614). 


\section{References}

Agasisti T, Arnaboldi M, Azzone G (2008). Strategic management accounting in universities: the Italian experience. Higher Education, 55(1):1-15

Ahn H-S, Righter R, Shanthikumar JG (2005). Staffing decisions for heterogeneous workers with turnover. Mathematical Methods of Operations Research, 62:499-514

ANECA (2014). Agencia Nacional de Evaluación de la Calidad y Acreditación. ANECA website. URL: http://www.aneca.es. Access date: $20 / 06 / 2013$

AQU (2014). Agència per a la Qualitat del Sistema Universitari de Catalunya. AQU website. URL: http://www.aqu.cat. Access date: $20 / 06 / 2013$

Birnbaum, R. (2000). The life cycle of academic management fads. Journal of Higher Education, 71(1), 1-15

Clark BR (1998).Creating Entrepreneurial Universities: Organizational Pathways of Transformation. Oxford: IAU Press by Pergamon 116

Clark BR (2003). Sustaining Change in Universities: Continuities in Case Studies and Concepts. Tertiary Education and Management, 9:99-

Corominas A, Lusa A, Olivella J (2012). A detailed workforce planning model including non-linear dependence of capacity on the size of the staff and cash management. European Journal of Operational Research 216(2):445-458.

Geng N, Jiang Z (2009). A review on strategic capacity planning for the semiconductor manufacturing industry. International Journal of Production Research 47(13):3639-3655

Geng N, Jiang Z, Chen F (2009). Stochastic programming based capacity planning for semiconductor wafer fab with uncertain demand and capacity. European Journal of Operational Research, 198:899-908 NJ.

Holt, C.C., Modigliani, F., Muth, J.F., Simon, H.A., 1960. Planning Production, Inventory and Work Force. Prentice Hall, Englewood Cliffs,

Hood, C. 1991. A Public Management for All Seasons?.Public Administration, 69: 3-19.

Hunt CM, Oosting KW, Stevens R, Loudon D, Migliore RH (1997). Strategic Planning for Private Higher Education. Binghamton, NY: Haworth

Jarzabkowski P (2003). Strategic Practices: An Activity Theory Perspective on Continuity and Change. Journal of Management Studies, 40:1

Lillis D (2006).Steering by engagement: towards an integrated planning and evaluation framework in Higher Education Institutes. European Forum for Quality Assurance: Embedding quality culture in higher education, Munich, Germany

Llinàs-Audet X, Girotto M, Solé F (2010). University strategic management and the efficacy of the managerial tools: the case of the Spanish universities. Revista de Educación, 355:33-54

Lounsbury M (2001). Institutional sources of practice variation: Staffing College and university recycling programs. AdministrativeScienceQuarterly, 46(1):29-56

Machuca JAD, González-Zamora MM, Aguilar-Escobar VG (2006). Service Operations Management research. Journal of Operations Management, 25:585-603

Maenhout B, Vanhoucke M (2013). An integrated nurse staffing and scheduling analysis for longer-term nursing staff allocation problems. Omega, 41:485-499

Ministry - Ministerio de Educación, Cultura y Deporte (2014). Ministry website. URL: http://www.mecd.gob.es. Access date: 16/09/2013

O'Brien-Pallas L, Birch P, Baumann A, Murphy GT (2000).Integrating workforce planning, human resources and service planning. Workshop on Global Health Workforce Strategy, Annecy, France

Ren-qian Z (2007). Research on capacity planning under stochastic production and uncertain demand. Systems Engineering - Theory \&Practice, 27 (1):51-59

Roth AV, Menor LJ (2003). Insights into Service Operations Management: a research agenda. Production and Operations Management; Summer 2003; 12 (2); ABI/INFORM Complete, 145

Rowley D, Lujan H, Dolence M (1997). Strategic Change in Colleges and Universities: Planning to Survive and Prosper. San Francisco: Jossey-Bass

Shattock M (2003). Managing successful universities. London, UK: Society for Research in Higher Education \& Open University Press

Song H, Huang H-C (2008). A successive convex approximation method for multistage workforce capacity planning problem with turnover. European Journal of Operational Research, 188:29-48

Starbuck WH (1992). Learning by knowledge-intensive firms. Journal of Operational Management Studies, 29 (6):713-740

Taylor J, Miroiu A (2002). Policy-making, strategic planning, and management of higher education. Papers on Higher Education. Regional University Network on Governance and Management of Higher Education in South East Europe. UNESCO

UPC - Universitat Politècnica de Catalunya · BarcelonaTech (2014). UPC website. URL: http://www.upc.edu. Access date: 15/03/2013

Wang KJ, Wang SM, Chen JC (2006). A resource portfolio planning model using sampling-based stochastic programming and genetic algorithm. European Journal of Operational Research, 184:327-340

Zeltyn S, Marmor YN, Mandelbaum A, Carmeli B, Greenshpan O, Mesika Y, Wasserkrug S, Vortman P, Shtub A, Lauterman T, Schwartz D, Moskovitch K, Tzafrir S, Basis F (2011). Simulation-based models of emergency departments: Operational, tactical, and strategic staffing. ACM Trans. Model.Comput.Simul. 21(4) 